\title{
Anterior chamber depth changes after retinal detachment
}

\author{
R. E. HARTLEY AND R. J. MARSH \\ From Moorfields Eye Hospital and the Western Ophthalmic Hospital, London
}

Glaucoma is a rare complication of retinal detachment surgery. Smith (1967) reporte postoperative angle closure in 4 per cent. of I, ooo consecutive scleral buckling procedures He believed the mechanism to be a forward rotation of the ciliary body with shallowing of the anterior chamber and angle closure. Fiore and Newton (1970) investigated 34 patients after scleral buckling with encirclement and found that four were shallow afte 2 months; the remainder became shallow temporarily but had returned to preoperative levels in 2 months. One of these had a choroidal detachment which recovered. We have set out to pursue these findings further: firstly, to compare anterior depth changes aftef various types of detachment surgery, and secondly, to investigate the early postoperative period.

\section{Methods}

Patients suffering from untreated retinal detachments presenting at Moorfields Eye Hospital and $\stackrel{\mathbb{\infty}}{\mathcal{2}}$

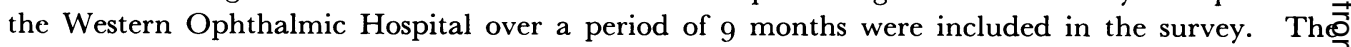
patients were assessed preoperatively as follows: a history was recorded with emphasis on any previous family incidence of glaucoma. Visual acuities and refractive errors were noted. Applan ation values, with pupils dilated, were taken. Gonioscopy was performed, recording the angles as deep, medium, or shallow (a short note was added on the trabecular appearance). The anterio응. chamber depths were measured with the Haag-Streit Type 2 Pachometer (Lowe, I966) when the pupils were dilated. The corneal thickness was measured and then the distance from the anterio $\frac{3}{5}$ corneal surface to the anterior lens capsule. The instrument provides a reliable comparative reading without further correction. Operative procedures were documented to include the use of osmotic agents, the type and size of plomb or encircling strap, its average distance from the limbus, any? muscles detached, any drainage of subretinal fluid, the number of quadrants treated with cryo $\frac{7}{2}$ therapy, and operative complications, such as vitreous or choroidal haemorrhages, paracentesis and, lastly, in some cases, applanation on completion.

Postoperative readings were made of anterior chamber depth and applanation. Gonioscopy was carried out if any marked shallowing occurred. These readings were taken on the first postoperativ $\mathbb{E}^{N}$ day, if possible, and at least twice in the first week. Readings were continued weekly until th@ preoperative depth was regained or for a follow-up period of at least 3 months in all other cases.

\section{Results}

A total of $5^{6}$ patients was examined and they were divided into four main groups (Table I)

The amount of shallowing of the anterior chamber, the time that this occurred, and any special comments are set out in Tables II to V. 
Table I Four main groups totalling $5^{6}$

patients

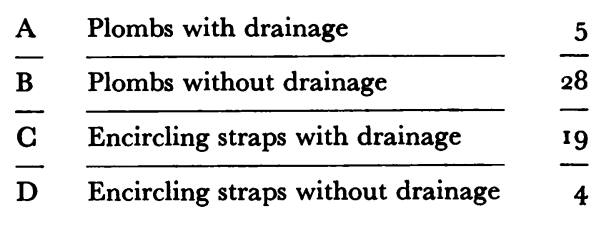

GROUP A Plomb with drainage. Five patients in four of whom the chambers became shallow (Table II).

Table II Plombs with drainage

\begin{tabular}{|c|c|c|c|c|}
\hline \multirow{2}{*}{ Patient no. } & \multicolumn{3}{|c|}{ Amount of shallowing of anterior chamber $(\mathrm{mm})}$. & \multirow{2}{*}{$\begin{array}{l}\text { Comments } \\
\text { on retina }\end{array}$} \\
\hline & First 3 days & End of first week & Late & \\
\hline $\mathbf{I}$ & $0 \cdot 6$ & $0 \cdot 6$ & nil & Flat \\
\hline 2 & $0 \cdot 9$ & $0 \cdot 7$ & $0 \cdot 6$ & Detached \\
\hline 3 & $0 \cdot \mathbf{I}$ & nil & nil & Flat \\
\hline 4 & $0 \cdot 5$ & 0.25 & nil & Flat \\
\hline
\end{tabular}

Special remarks on Group $A$

Case 2 Corneal oedema was present from the second day. The retina remained detached. The eye was encircled I week later with no success and strap pain was experienced.

GROUP B Plomb without drainage. 28 patients, in thirteen of whom the anterior chamber became shallow (Table III, overleaf).

\section{Special remarks on Group B}

Case $x$ At the first week small choroidal detachments were seen nasally. At Day 12 the angle was closed for $180^{\circ}$. At 4 weeks iris atrophy was seen and the retina re-detached. The tension was not raised at any time.

Case 2 At 10 days ring choroidal detachments were present and the angle closed nasally and temporally.

Case 7 Had unchanging residual fluid which could well be due to a previous schisis.

Case 13 Vitreous haemorrhage occurred during surgery. The retina re-detached on Day 7. The patient was re-operated on twice but the retina remained detached.

GROUP G Encirclement with drainage. Nineteen patients of whom seven shallowed, one deepened, and eleven remained unchanged (Table IV, overleaf).

Special Remarks on Group $C$

Case 2 On Day 2 there was iridocorneal contact with glaukomflecken; tension was uncontrolled medically and on Day 4 the strap was cut. The glaucoma resolved but sectoral iris atrophy ensued. Case 3 Raised tension occurred on Day I; $2 \cdot 6$ per cent. of the angle was closed. The tension was 
Table III Plombs without drainage

\begin{tabular}{|c|c|c|c|c|}
\hline \multirow{2}{*}{ Patient no. } & \multicolumn{3}{|c|}{ Amount of shallowing of anterior chamber $(\mathrm{mm})}$. & \multirow{2}{*}{$\begin{array}{l}\text { Comments } \\
\text { on retina }\end{array}$} \\
\hline & First 3 days & End of first week & Late & \\
\hline $\mathbf{I}$ & - & $0 \cdot 5$ & $0 \cdot 1$ & Detached \\
\hline 2 & - & 0.5 & nil & Flat \\
\hline 3 & - & $1 \cdot 2$ & nil & Flat \\
\hline 4 & - & $0 \cdot 8$ & 0.5 & Flat \\
\hline 5 & $0 \cdot 2$ & $0 \cdot 2$ & $0 \cdot 1$ & Flat \\
\hline 7 & $0 \cdot 3$ & nil & nil & $\begin{array}{l}\text { Residual } \\
\text { fluid }\end{array}$ \\
\hline 8 & $0 \cdot 15$ & nil & nil & Flat \\
\hline 9 & $0 \cdot 2$ & $0 \cdot 15$ & $0 \cdot 4$ & Flat \\
\hline 10 & 0.15 & $0 \cdot 1$ & nil & Flat \\
\hline I I & 0.2 & $0 \cdot 2$ & nil & Flat \\
\hline 12 & $0 \cdot I$ & $0 \cdot 2$ & $0 \cdot 2$ & Flat \\
\hline 13 & 0.5 & 0.4 & - & Detached \\
\hline
\end{tabular}

Table IV Encirclement with drainage

\begin{tabular}{|c|c|c|c|c|}
\hline \multirow{2}{*}{ Patient no. } & \multicolumn{3}{|c|}{ Amount of shallowing of anterior chamber $(\mathrm{mm})}$. & \multirow{2}{*}{$\begin{array}{l}\text { Comments on } \\
\text { retina }\end{array}$} \\
\hline & First 3 days & End of first week & Late & \\
\hline I & $0 \cdot 4$ & $0 \cdot 6$ & - & Flat \\
\hline 2 & $\mathbf{I} \cdot 3$ & $I \cdot I$ & nil & Flat \\
\hline 3 & $1 \cdot 3$ & $0 \cdot 8$ & $0 \cdot 8$ & Flat \\
\hline 4 & $0 \cdot 4$ & $0 \cdot 3$ & nil & Flat \\
\hline 5 & $0 \cdot 15$ & $1 \cdot 2$ & - & Re-detached \\
\hline 6 & $0 \cdot 5$ & $0 \cdot 9$ & $0 \cdot 3$ & Flat \\
\hline 7 & $0 \cdot 3$ & $1 \cdot 0$ & 0.5 & Re-detached \\
\hline
\end{tabular}

uncontrolled medically and on Day 7 a peripheral iridectomy was carried out. The glaucom结 resolved over the next 3 weeks with a slow initial response.

Case 4 A giant tear was present.

Case 5 There was an inferior coloboma of iris ciliary body and choroid. The retina was flat of Day 3 but then slowly detached. The strap was tightened 2 months later with only temporary success.

Case 6 Choroidal detachments were seen on Day 5, but slowly resolved.

Case 7 There was a total detachment with incipient massive vitreous retraction. On Day the retina remained detached and there was strap pain. Massive vitreous retraction occurre 
Table $\mathbf{V}$ Encirclement without drainage

\begin{tabular}{|c|c|c|c|c|}
\hline \multirow{2}{*}{ Patient no. } & \multicolumn{3}{|c|}{ Amount of shallowing of anterior chamber $(\mathrm{mm})}$. & \multirow{2}{*}{$\begin{array}{l}\text { Comments on } \\
\text { retina }\end{array}$} \\
\hline & First 3 days & End of first week & Late & \\
\hline I & $0 \cdot 3$ & nil & nil & Flat \\
\hline 2 & $0 \cdot 1$ & nil & - & Re-detached \\
\hline 3 & $0 \cdot 6$ & nil & nil & Flat \\
\hline 4 & $0 \cdot 6$ & 0.5 & nil & Flat \\
\hline
\end{tabular}

GROUP D Encirclement without drainage. Four patients, in all of whom the anterior chamber became shallow (Table V)

Special remarks on Group $D$

Case 2 The retina was flat for 5 weeks, but massive vitreous retraction then occurred with total retinal detachment. Re-operation with a shoe under the encircling strap and intravitreal silicone fluid failed to achieve flattening.

Case 4 Choroidal detachments were seen at the $5^{\text {th }}$ postoperative day but had resolved by the roth.

Early shallowing of the anterior chamber occurred in 28 cases and deepening in one of the total of $5^{6}$ cases. Seventeen of the 28 followed local procedures and eleven followed encirclements. $5^{2}$ per cent. of those treated by local procedures and $4^{8}$ per cent. of the encirclements showed shallowing in the early postoperative period. Our findings of corneal thickening postoperatively were the same as those of Fiore and Newton (1970), viz. a temporary small increase in nearly all eyes, returning to normal within 2 weeks.

The amount of cryotherapy and the size of the plomb or strap did not seem to influence this shallowing. The present series is not large enough to show whether drainage or non-drainage of subretinal fluid influences the anterior chamber depth, but it was interesting to observe how rapidly the normal depth was fully recovered after major buckling procedures, with no drainage of subretinal fluid and with paracentesis.

\section{Discussion}

In a series of 160 cases of retinal detachment investigated by Sebastyen, Schepens, and Rosenthal (I962), postoperative raised intraocular pressure was seen to occur in fourteen. The authors noted that the following factors were related to this increase:

(I) Changes in the filtration angle (such as peripheral anterior synaechiae, narrow angle, and increased pigmentation of the trabecular meshwork)

(2) Duration of the detachment

(3) Multiple retinal operations

(4) Surgical aphakia.

The series studied in this paper were fresh phakic cases, thus eliminating two of the factors mentioned. None had any previous or family history of glaucoma or obvious angle abnormality preoperatively.

The cases in which the anterior chamber became shallow tended to fall into two groups:

(I) Those with a small amount of shallowing $(0 . \mathrm{I}-0.6 \mathrm{~mm}$.) which was usually present 
on the first postoperative day and was unaccompanied by other changes except for increased corneal thickness. Preoperative anterior chamber depth was usually regained with $\underline{\underline{B}}$ I month.

(2) Those with a greater degree of shallowing (approximately I $00 \mathrm{~mm}$.), which waे not necessarily present on the first day, but developed within the first week. TT shallowing was accompanied by other changes: notably a change in intraocular pressu的 and choroidal detachments.

Permanent shallowing tended to occur in unsuccessfully treated cases. As can be se约 from the Tables, there was a large proportion of the Group I type of shallowing in thos treated by the local procedures. In contrast, there was a larger proportion of Group $\underline{H}$ response in the cases treated by encirclement.

The Group I response is a benign condition and possibly occurred because of temporaty displacement of the ciliary body by the buckling procedure, causing relaxation of the leins iris diaphragm and allowing the lens to move forwards.

The Group II response is a serious condition with a poor prognosis for success. Tiq eyes in this group were presumably poorly able to deal with the physiological readjustments subsequent to the detachment surgery. Possibly this is because the eyes are originally on the border-line of anterior segment ischaemia. Several of our patients showed ischaem manifestations postoperatively. This group is being further examined at present.

\section{Summary}

$5^{6}$ patients were examined before and after retinal detachment surgery. Special emphasis was placed on changes in anterior chamber depth, intraocular tension, and the type 8 surgery. $\quad 5^{2}$ per cent. of the local buckling procedures and $4^{8}$ per cent. of the encirclemen were followed by shallowing of the anterior chamber in the early postoperative perio $\bar{\delta}$. Permanent shallowing occurred more commonly after encirclements and carried a poôr prognosis.

We should like to acknowledge the help of Messrs. L. G. Fison and J. H. Redmond Smith, and to thank them and the surgeons of the Western Ophthalmic Hospital for permission to report their cases.

\section{References}

FIORE, J. v., and NEwton, J. c. (1970) Arch. Ophthal. (Chicago), 84, 284 LOWE, R. F. (1966) Amer. F. Ophthal., 62, 7 Sebestyen, J., Schepens, c. L., and rosenthal, m. L. (1962) Arch. Ophthal. (Chicago), 67, 736 sмiтн, т. R. (1967) Amer. F. Ophthal., 63, 1807 